\title{
Local food sales and point of sale priming: evidence from a supermarket field experiment
}

\author{
Ružica Brečić, Dubravka Sinčić Ćorić and Andrea Lučić \\ Department of Marketing, Faculty of Economics and Business, \\ University of Zagreb, Zagreb, Croatia \\ Matthew Gorton \\ Newcastle University Business School, Newcastle University, \\ Newcastle upon Tyne, UK, and \\ Jelena Filipović \\ Faculty of Economics, Univerzitet u Beogradu, Beograd, Serbia
}

\begin{abstract}
Purpose - An intention-behavior gap often occurs for socially responsible consumption, where despite positive consumer attitudes, sales remain disappointing. This paper aims to test the ability of in-store priming to increase sales of local foods vis-à-vis imported, cheaper equivalents.
\end{abstract}

Design/methodology/approach - Laboratory and field experiments in three countries (Croatia, Slovenia and Serbia), working with an international grocery retailer, assess the ability of textual and pictorialbased point of sale (PoS) materials to increase the purchase of local foods. Field sales data, for the purchase of local apples and cherries and their imported equivalents, are complemented by an analysis of loyalty card transactions.

Findings - Field data indicate that both pictorial and textual PoS materials, significantly increase the likelihood of purchasing local foods, against cheaper imported equivalents. Pictorial PoS materials appear more effective than textual equivalents. Laboratory study data indicate that PoS materials increase the salience of goal consistent mechanisms in decision-making at the expense of mechanisms to achieve nonprimed goals.

Research limitations/implications - The field experiment lasted for only two weeks and focused on seasonal produce.

Practical implications - PoS materials offer a low cost intervention for modifying consumer behavior in stores.

Originality/value - The paper develops a theory regarding how priming works and its application in a supermarket setting. This is investigated and validated in the context of local foods. The study offers

(C) Ružica Brečić, Dubravka Sinčić Ćorić, Andrea Lučić, Matthew Gorton and Jelena Filipovic. Published by Emerald Publishing Limited. This article is published under the Creative Commons Attribution (CC BY 4.0) licence. Anyone may reproduce, distribute, translate and create derivative works of this article (for both commercial and non-commercial purposes), subject to full attribution to the original publication and authors. The full terms of this licence may be seen at http:// creativecommons.org/licences/by/4.0/legalcode

This paper draws on research conducted as part of the Strength2Food project, which received funding from the European Union's Horizon 2020 research and innovation programme under grant agreement No. 678024.

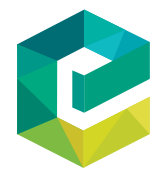

European Journal of Marketing Emerald Publishing Limited Emerald Publishing Limited
$0309-0566$ DOI 10.1108/EJM-07-2019-0604 
encouragement for the usefulness of other in-store primes, such as relating to diet, to improve socially desirable outcomes without economic incentives or coercion and in a cost-effective manner.

Keywords Supermarkets, Field experiment, Priming, Local foods

Paper type Research paper

\section{Introduction}

Recent years witnessed a growing interest in ethical consumption - "consumption activities that are consistent with conscience, values and morals" (Reczek and Irwin, 2015, p. 507). Greater numbers of consumers, particularly young adults, identify that they value ethical and socially responsible perspectives in their buying decisions (Andrews et al., 2014) and survey and experimental evidence point toward strong support for more environmentally friendly and socially/ethically responsible foods (Van Loo et al., 2014; Leonidou and Leonidou, 2011). However, a substantial intention-behavior gap exists between self-reported preferences for socially/ethically responsible products and their sales (Campbell and Fairhurst, 2016; Carrington et al., 2010; Carrington et al., 2014). For instance, FUTERRA (2005) reports that while $30 \%$ of consumers state they would purchase "ethically," only $3 \%$ actually do so. Developing and verifying strategies to reduce intention-behavior gaps for socially/ethically responsible purchases is an important objective for academics and practitioners working in green and cause-related marketing (Carrington et al., 2014; Govind et al., 2019). This paper addresses this objective by investigating the effectiveness of textual and pictorial-based point of sale (PoS) primes for reducing intention-behavior gaps, considering the case of local foods in supermarkets.

Extant literature identifies several reasons for intention-behavior gaps. As part of their integrated model of behavioral prediction, Fishbein and Yzer (2003) argue that while intentions are the best predictor of behavior, the latter also depends on the presence of environmental constraints and necessary skills. Recent work also considers self-control failures, which are important in explaining differences across individuals in their likelihood to enact behavioral intentions (Rogers and Milkman, 2016). However, two other important factors as to why intentions go unexecuted are that people simply forget to do what they intended (memory lapses) and, second, individuals have multiple, often competing, goals, which may "crowd out" or override the achievement of others in a particular context and time period (Carrington et al., 2014; Corradi et al., 2013; Lagerkvist and Okello, 2016; Shah and Kruglanski, 2003).

Memory lapses may lead to an intention-behavior gap even for activities deemed important, beneficial and easy to perform. For instance, research with women who intended but had not performed breast self-examinations to check for signs of cancer revealed that for $70 \%$ the primary reason was that they forgot (Orbell et al, 1997). Regarding crowding out, previous research establishes that ethical values must be salient at the point of purchase to affect action e.g. selecting one offering from completing alternates (Verplanken and Holland, 2002). Consumers typically seek to accomplish multiple goals (helping others and frugality), which often involve trade-offs when making purchase decisions e.g. an "ethical" offering may be more expensive. The nature of the environment in which decision-making occurs influences how consumers resolve trade-offs (Carrington et al, 2010), so, for example, thrift-based environmental primes increase the probability of consumers choosing value-based products (Laran et al, 2011), while prestige cues reverse the effect (Chartrand et al., 2008). In a supermarket shopping environment, price and price-related primes are typically ubiquitous (Lichtenstein et al., 1993). In this context, frugality as a goal may take precedence over ethicality, even if ethical values matter to the consumer, as the activation of money saving goals in a retail shopping environment is far stronger (Reczek and Irwin, 2015; Chartrand et al., 2008). Consequently, the goal of saving money may crowd out intentions to 
purchase ethically/socially responsible goods in a typical retail environment, as in the absence of goal-activating stimuli, ethical goals remain "out of sight, out of mind" (Shah and Kruglanski, 2003).

The importance of memory lapses and the ubiquity of price-based cues activating moneysaving goals in supermarket environments suggests a potential role for aide-mémoire priming stimuli that remind individuals of an existing goal to purchase ethically/socially responsible goods. Such primes can aid goal accomplishment by helping individuals keep their "eye of the prize" in the context of competing demands on attention and effort (Shah and Kruglanski, 2003). This could be, as investigated here, in the form of PoS materials, which remind shoppers of specific goals in a retail environment. So, the question becomes to what extent can non-pricebased environmental primes reduce the intention-behavior gap for more ethically/socially responsible purchases?

This paper investigates the effectiveness of textual and pictorial-based primes for increasing sales of local foods in a supermarket context. Local foods are a form of ethical consumption as moral and personal beliefs underpin choices, albeit in combination with egoistic concerns (Birch et al., 2018). Specifically, moral and personal beliefs relating to supporting local farmers, food producers and territories are integral to the appeal of local foods (Megicks et al., 2012). After laboratory testing, we conducted a field experiment with an international grocery retailer in supermarkets across three countries (Croatia, Serbia and Slovenia). For Croatia, sales data are supplemented with an analysis of loyalty card transactions to better understand, which market segments are more likely to respond to priming.

The paper contributes on two main grounds. First, we introduce priming as a mechanism for reducing the intention-behavior gap for more ethically/socially responsible purchasing. We develop a theory as to how it may work in a retail setting, leading to a set of hypotheses for testing. Whilst a substantial literature on priming effects exists, demonstrating how objects and props can create distinct contexts and exert unconscious effects on behavior (Cadario and Chandon, 2020; Chartrand et al., 2008; Sela and Shiv, 2009; Weingarten et al., 2016), this is largely limited to laboratory and restaurant/canteen environments, leading to calls that "precedence should be given to testing interventions in grocery stores and outside the US," with greater attention to reporting effects for different segments and sub-groups of the population (Cadario and Chandon, 2020, p. 468). Chabris et al. (2019) argue that the priming literature is too dependent on small samples and laboratory-based studies, which typically consider the effect of a single type of prime in isolation. In store, shoppers face a multitude of primes, overwhelmingly focused on price considerations (discounts, sale signs etc). and previous research fails to consider whether $\mathrm{PoS}$ materials, priming non-price-based norms, can be effective and with whom in such an environment. For retailers, this is of practical importance (Wansink, 2017).

Second, we investigate priming in the context of local foods. There is growing consumer, retailer and policy interest in the sale of local and regional foods (Yang et al., 2020), which may stimulate economic development, particularly in rural economies characterized by low incomes and outmigration (Kneafsey, 2012; Barlagne et al., 2015; Arfini, 2019). This is true of South-eastern Europe, where the field experiment occurred, which possesses large numbers of small-scale farms. Previous survey work in Western Europe and North America identifies a sizable group of consumers who value the localization of food production and claim that they are willing to pay extra for it (Weatherell et al., 2003; Tregear and Ness, 2005; Chambers et al., 2007; Onozaka and McFadden, 2011; Abrams and Soukup, 2017; Toler et al., 2009), a finding also replicated in the region of study (Barjolle et al., 2013). However, local produce linked to a specific geographical origin (region and country) typically lacks cost competitiveness compared with generic versions, which can be sourced from numerous territories. This leads to multiple retailers being reluctant to stock local products, citing insufficient demand (Feldmann and Hamm, 2015). Where available, sales of local foods are lower than forecasted based on 
consumer surveys, suggesting a substantial intention-behavior gap (Campbell and Fairhurst, 2016; MINTEL, 2013). However, as noted by Abrams and Soukup (2017), there is a paucity of communications research on local foods, with few attempts to manipulate labeling and promotional materials. Accordingly, they call for further research using field experiments to gain "a better understanding of local food messaging" and its effectiveness (Abrams and Soukup, 2017 p. 14).

\section{Local foods}

There is no universally accepted definition of a local food (Martinez et al., 2010). Most approaches consider the geographical distance between the point of production and consumption (e.g. 30 miles or $50 \mathrm{~km}$ ) or that which is produced and consumed within a specific political entity such as a state, region or country (Racine et al., 2013; Bingen et al., 2011). For instance, the 2008 US Farm Act defines a local food as that which is sold within 400 miles of its origin or within the State in which it is produced (Martinez et al., 2010).

Previous work maps consumers' attitudes regarding local foods. Older (Megicks et al., 2012; Weatherell et al., 2003), richer (Brown et al., 2009), rurally located (Racine et al., 2013; Megicks et al., 2012) and female (Megicks et al., 2012; Weatherell et al., 2003) consumers typically hold more favorable attitudes to local foods. While meaning different things to different people, local food embodies a values-based consumer awareness and decisionmaking (Bingen et al., 2011). Prior research identifies two broad sets of motives. Intrinsic motivations reflect a perceived superiority in terms of sensory properties, especially freshness and health benefits (Weatherell et al., 2003; Megicks et al., 2012; Chambers et al., 2007). Extrinsic motivations, in contrast, refer to wider concerns connected with supporting local economies, especially farmers (Toler et al., 2009), the environment and community cohesion, which "go beyond the act of eating" (Bingen et al., 2011). Generally, intrinsic motivations are of greater salience in food choice than civic factors (Weatherell et al., 2003; Megicks et al., 2012).

While attitudes toward, and stated intentions to consume, local foods are typically favorable (Megicks et al., 2012), its share of total food purchases remains low (Chambers et al., 2007; MINTEL, 2013). In respect to this gap, McEachern et al. (2010) argues that consumers of local foods are also flexible consumers - so that ethical concerns have to fit with the achievement of other goals relating to time, price and convenience. These are often in conflict and not resolved consistently, so that behavior can be unpredictable and heavily context-dependent. Tregear and Ness (2005) draw a similar conclusion, noting that the importance ratings of price and intrinsic quality attributes do not differ significantly according to the level of interest in local food, implying that even those with the most favorable outlook have other, important expectations that lead to pragmatic decision-making. In this regard, local foods are similar to other forms of ethical food consumption (Reczek and Irwin, 2015; Van Doorn and Verhoef, 2015).

\section{Theory}

Priming refers to the activation of mental constructs and behavioral concepts, through supraliminal or subliminal means, via perception of external stimuli (Weingarten et al., 2016). The effect of primes may occur in multiple ways. The simplest mechanism involves primes directing individuals' attention consciously to previously formed goals (Shah and Kruglanski, 2003). For instance, reminder systems, be it computer generated automatic cues or manually derived ones, boost take-up of health screening and other preventative services (Zapata $e t$ al., 2018). However, goal constructs can be activated in memory without conscious guidance were associated with a particular cue (stimulus-response conditioning). Once a goal is activated, 
strategies associated with that goal are also activated and direct subsequent behavior (Chartrand et al., 2008; Bargh, 2017; Shah and Kruglanski, 2003). Brands and other commercial stimuli can activate goals outside of conscious awareness (Fransen et al., 2008). For instance, subliminally priming a retail brand associated with thrift (Wal-Mart) led consumers to behave in ways consistent with the related goal, selecting value-based options over more prestigious alternates (Chartrand et al., 2008). Similarly, video-game players when driving a Red Bull branded car drove faster but more recklessly than in other branded cars (e.g. Tropicana and Coca-Cola), without participants' awareness (Brasel and Gips, 2011).

Central to theories of priming is the notion that goals are represented in mental structures, which include the positive valence of an associated state (Custers and Aarts, 2005; Custers and Aarts, 2010). Consequently, goal representation not only specifies the desired state but also its desirability. Non-conscious operation of a behavioral goal, therefore, depends on whether positive affect is linked to the mental representation of the respective state, which when present automatically signals that the state is worth pursuing (Custers and Aarts, 2005; Veltkamp et al., 2011). Primed goals affect motivation outside of awareness because the mental representation of goals is positive and priming such goals activates a positive affective tag, which operates as a reward signal (Custers and Aarts, 2010; Veltkamp et al., 2011).

Given this theoretical framework, we expect PoS material promoting local foods to increase their sales, among a population predisposed to local foods, through two mechanisms. First, consciously, as a reminder directing attention to previously formed goals (Shah and Kruglanski, 2003). PoS materials in store should be particularly effective as an aide-mémoire, as they are encountered when consumers make purchasing decisions, and thus, when previously formed intentions can be enacted (Rogers and Milkman, 2016; Austin et al., 2006). Second, viewing of PoS material can lead to non-conscious activation of a positively assessed goal, stimulating choices consistent with the primed concept (Custers and Aarts, 2010). Given that priming occurs in store, an individual's ability to makes choices consistent with an activated goal is high and almost instantaneous, so that the possibility of goal fulfillment is high and quick (Sela and Shiv, 2009). Consequently, we expect that:

H1. Choice of a product linked to a behavioral goal will be higher in the presence of PoS materials promoting that goal.

Several accounts of the mechanisms underlying priming effects exist, with recent theory focusing on the role of activated motivational constructs (Fitzsimons et al., 2008; Weingarten et al., 2016). According to the latter, goals can be activated by environmental stimuli (situational cues) either consciously or non-consciously and goals are desired states that individuals wish to attain (Custers and Aarts, 2010; Shah and Kruglanski, 2003). For instance, those exposed unobtrusively to words invoking prestige goals are more likely to select, in a lab experiment, higher priced, Nike branded socks than those in a thrift-condition control group (Chartrand et al., 2008). Such effects occur because activated goals cause ways to achieve such a goal to become more accessible (Fitzsimons et al., 2008; Shah et al., 2002). Consequently, goal activation leads to the means to achieving that goal to become active (Fitzsimons et al., 2008). Priming, however, only works where it is congruent with an individual's current goals. For instance, priming a drink's brand name increases its selection and fluid intake but only for those who are thirsty (Karremans et al., 2006). Priming local foods will only thus, affect sales among those predisposed to them and, for instance, among highly neophobic consumers, primes for foods alien to their culture are likely to be ineffective.

In the case of PoS priming, we expect that the goals primed in the display to become active among those predisposed to the goal, so that mechanisms to achieve that goal also 
consequently become active. This increases their salience in decision-making. While, consumers typically possess multiple, often competing goals, their salience at the point of decision-making varies. Priming one goal increases its salience and typically comes at the expense of a quest to reconcile multiple, competing other goals (Kopetz et al., 2012). In other words, the salience of the primed goal increases at the expense of non-primed goals. For instance, among consumers who seek both food enjoyment and weight control, when the former goal is experimentally heightened, participants select more foods that are instrumental to that goal regardless of caloric content (Study 4, Köpetz et al., 2011). Heightening the food enjoyment goal, crowded out the weight control motivation. In the case of local foods, priming the goal of supporting domestic farmers and producers, should activate mechanisms to achieve this goal (buying local foods) at the expense of non-primed goals such as frugality. Consequently, we expect that:

H2. PoS materials priming a particular goal, activate mechanisms to achieve that goal, increasing the salience of goal consistent mechanisms in decision-making at the expense of mechanisms to achieve non-primed goals.

Construal level theory (CLT) explains how individuals mentally construe objects that are psychologically near in terms of low-level, concrete and contextualized features, but use abstract, high level construals for comprehending psychological distant objects or events (Trope et al., 2007). Research indicates that advertising messages are more effective when they evoke construal levels that are congruent with viewers' psychological distance (Martin et al., 2009). Psychological distance has several dimensions including space, time and social distance (Hernandez et al., 2015). For instance, regarding time, message elements should be consistent with purchase time frames, so that immediate purchases should be matched with concrete, attribute specific information and guarantees (Jin and He, 2013).

Pictures convey referent objects, impart a sense of proximity and invoke concrete perceptions, while words invoke the "abstract essence of referent objects" (Choi et al., 2019, p. 530). Consequently, pictures should match psychologically close objects and text congruent with psychologically distant ones (Trope et al., 2007). Empirical evidence is consistent - pictures are more persuasive for proximal consumption events, while text is preferable for distant consumption events (Choi et al., 2019; Lee et al., 2009). Using advertisements of fruit and furniture, Choi et al. (2019) found that pictures evoke more favorable attitudes to the brand and purchase intention for non-durable goods for immediate consumption (fruit) but that textual-based advertisements elicit more favorable responses for durable goods where psychological distance is greater (furniture). While there is an absence of previous studies comparing textual and pictorial PoS materials, based on CLT and related empirical evidence for fruit advertisements it is assumed that:

H3. For psychologically close objects, congruent pictorial-based PoS materials are more effective at increasing sales than textual-based PoS materials.

\section{Methodology}

The pre-experimental phase included an in-store intercept survey, qualitative research and pre-test. The intercept survey involved food shoppers in-store in Croatia $(n=96)$, Serbia $(n=101)$ and Slovenia $(n=108)$. Shoppers were intercepted at random and of those approached, approximately $40 \%$ refused to participate with the most common reason given being insufficient time. The in-store survey sought to check shoppers' degree of support for buying local foods. On a seven-point scale, where $1=$ equals strongly disagree and 
$7=$ strongly agree, respondents indicated their degree of support for the statements "buying local produce is a significant cause" (mean $=5.95$ ), "buying local produce is important to me" (mean $=5.74)$ and "buying local produce will benefit farmers" (mean $=6.25)$. Taken together the results indicate positive consumer attitudes toward local food across the three countries studied, albeit with stronger support in Croatia and Slovenia than Serbia. For instance, regarding "buying local produce is a significant cause," the mean scores for Croatia, Serbia and Slovenia were 5.94, 5.52 and 6.36, respectively $(F=8.677, p=0.000)$. Serbia has lower average incomes and a significantly higher proportion of the population living in poverty, based on national poverty lines.

To generate further insights, we conducted two focus groups. Focus group 1 consisted of eight women, aged between 28 and 42 years of age, 6 of whom had children. Focus group 2 consisted of 8 women, aged between 28 and 52, 6 of whom had children. All were: used (with a mix of occupations e.g. nurse, teacher, lawyer and entrepreneur), the primary food shopper in their household, and purchased fresh fruits regularly. The focus groups occurred in Zagreb (capital of Croatia). The focus groups addressed four main issues, namely, patterns of fresh fruit purchases and consumption, the motivations affecting fruit purchases, how shoppers make judgments regarding fresh fruit quality and what they look for in-store and understanding of the term "local food" and its associations. Discussions were recorded and transcripts subject to thematic analysis (Braun et al., 2019). The focus groups established that Croatians perceive local as applying to the whole country, rather than a specific region or subterritory. This reflects the relatively small size of the country and the predominance of national over (sub)regional identities - a pattern, which also holds for Slovenia and Serbia. When discussing local, participants implied the country rather than a particular village, town or region and this conceptualization informed the empirical research.

Three salient motivations for buying local produce emerged, namely, perceived superior quality (freshness and taste), health benefits and to support the country's farmers. These are consistent with the intrinsic and extrinsic motivations identified in the literature (Bingen et al., 2011; Weatherell et al., 2003). Participants believed local fruits to be fresher, and therefore, more nutritious and "natural," delivering health benefits, as well as tastier. However, several participants also discussed an ethical dimension, believing buying local was morally right, to support the livelihood of fellow citizens "because there is a problem because most young people moved because they cannot find work [...] when I decide to buy I always prefer to buy something from a local manufacturer." As another noted, this may override the consideration of intrinsic attributes: "I will always buy a Croatian product, not because it is healthier or better but because it is Croatian."

The intercept survey and focus group findings served as a starting point for the development of in-store materials. We appointed a professional marketing agency to develop two types of instore PoS promotional materials. The first type included photographs and the second group consisted of textual messages emphasizing the potential benefits of buying local food in line with the focus group findings. The potential PoS materials were pre-tested for appeal and perceived understanding, via an on-line self-administered questionnaire $(n=58)$ in which respondents rated specific images and textual messages. The results of the survey informed the decision on which photograph, and specific textual messages were used in the in-store experiment. The finalized pictorial-based PoS material consisted of a young, male farmer with a basket full of fresh fruits and vegetables, and a small photograph of the relevant national flag in the corner of the photo. The online survey responses for the selected photograph, on a five-point Likert scale $(1=$ strongly disagree and $5=$ strongly agree), yielded mean scores of 4.29, 4.03 and 4.19 for the statements "this image is appropriate for the promotion of fruits and vegetables," "this image is useful" and "I like this message," respectively. The textual PoS material consisted of three messages, namely, 
I buy local; I buy it fresher; I support the local farmer. These were the three highest-rated messages (mean scores of 4.05, 4.10 and 4.10) and consistent with the focus group findings. This suggests that the materials are effective and communicate intended meanings. Appendix details the sample PoS materials and a picture illustrating their application in-store.

A final pre-test, following Mandel and Johnson (2002), checked message equivalence in goal activation between the textual and pictorial PoS materials. In total, 186 students at a Croatian university were randomly assigned to view either the textual $(n=85)$ or pictorial $(n=101)$ PoS materials (as displayed in Appendix), which were embedded within a Qualtrics hosted survey. After viewing materials, participants were asked what comes to mind when considering buying fruit and vegetables, with space for four, free text answers. In the case of the text-based prime, $64.7 \%$ mentioned origin or domestic as a consideration, while for the pictorial-based prime group the equivalent figure was $62.4 \%\left(X^{2}=0.762\right.$, $p=0.431$ ). This indicates no significant differences between the text and pictorial-based primes in terms of their ability to induce thinking regarding origin and the domestic economy (message equivalence regarding local/origin goal activation).

In summary, the pre-test phase established that consumers in the investigated countries possess a positive attitude toward local food, with the appeal based on perceived superior quality (freshness and taste), health benefits and a desire to supporting the country's farmers. We now turn to Studies 1 and 2, which focus on fresh apples and cherries. We selected these products because they are, namely, mainstream foods, readily available from both domestic and foreign producers for the same variety, and highly perishable. The latter implies little opportunity for hoarding so that consumers' purchase behavior reflects immediate preferences rather than a desire to stockpile (Ballings et al., 2018).

\section{Study 1a}

Study la provides an initial test of the ability of PoS materials to stimulate the choice of local foods, by increasing the salience of goal consistent mechanisms in decision-making at the expense of mechanisms to achieve non-primed goals.

\section{Design and procedure}

Within a computer lab setting, 153 undergraduate students at a Croatian university were randomly assigned into one of the three groups, namely, no prime $(n=51)$, textual prime $(n=50)$ and pictorial prime $(n=52)$. After an introduction, subjects viewed either the no, textual or pictorial primes (as displayed in Appendix) before being asked to imagine that they were in a supermarket and wished to purchase apples. They were told that for a specific variety of apples, there were two options, namely, Croatian apples, which cost 10 kuna (circa €1.35) per kilogram and Polish apples, which cost 7 Kuna per kilogram (circa $€ 0.95$ ). Subjects were asked to make a choice between the Croatian or Polish apples or select neither. After making a choice, subjects rated the certainty of their choice on a sliding scale $(0=$ not very certain and $100=$ very certain). Immediately after the choice, subjects reported the extent to which particular goals were in their mind when making the choice between apples ( $1=$ not considered at all in decision, $7=$ most important factor in the decision).

\section{Results and discussion}

A greater proportion of subjects in the textual $(74 \%)$ and pictorial (63.5\%) prime groups chose local apples, compared to the no prime $(51 \%)$ control group $\left(X^{2}=5.741, p=0.057\right)$, supporting $H 1$. There are no significant differences between the pictorial, textual and control groups in terms of the certainty of decision $(F=1.528, p=0.220)$. Consistent with $H 2$, significant differences across the groups are apparent in terms of subjects' rating of the 
importance of particular goals in their mind when making a choice (Table 1). Specifically, the rating of local origin and well-being of local farmers is higher in textual and pictorial prime groups compared to the non-primed control group. In contrast, those in the nonprimed group rated price as being of greater salience in their choice decision than those in the textual and pictorial prime groups.

A comparison of the word and pictorial prime groups indicates no significant differences in mean scores, apart from in the case of price, where the pictorial prime appears more effective in decreasing its salience $(t=1.941, p=0.055)$. Comparing the no prime and pictorial groups indicates significant differences in terms of the importance of price $(t=1.941, p=0.055)$, local origin $(t=-2.069, p=0.041)$, health $(t=-2.057, p=0.042)$ and well-being of local farmers $(t=-2.696, p=0.008)$ in the choice decision, but not freshness $(t=-0.254, p=0.800)$. Comparing the control and textual groups, however, the only significant difference in terms of salience in decision-making relates to the well-being of local farmers $(t=1.515, p=0.088)$. Yet, regarding the choice between Polish and Croatian apples, there are significant differences between the no prime and word $\left(X^{2}=8.396\right.$, $p=0.015)$ and no prime and pictorial prime groups $\left(X^{2}=6.737, p=0.034\right)$. There are no significant differences between the textual and pictorial primes in terms of the likelihood of choosing the local option $\left(X^{2}=0.173 p=0.677\right)$.

In summary, Study 1a provides initial evidence that PoS priming affects consumer choice, supporting $H 1$ and can change the salience of goal consistent mechanisms in decision-making, consistent with $H 2$, at the expense of mechanisms to achieve non-primed goals (e.g. frugality). However, in a computer lab setting, we do not find support for $H 3$ regarding the relative effectiveness of pictorial and textual-based PoS materials.

\section{Study $1 b$}

One concern is that the results of Study la might reflect specific country of origin (COO) effects. We, therefore, conducted a follow-up study using the descriptors local and imported for the apples instead of a specific COO (e.g. Croatia and Poland) [1].

\section{Design and procedure}

Participants were 240 different students from the same Croatian University as for Study 1a. Participants were randomly assigned to the no prime $(n=81)$ textual prime $(n=80)$ or pictorial prime condition $(n=80)$. Participants in the primed groups viewed the same primes as in the previous experiment, and again were asked to imagine that they were in a supermarket and wished to purchase apples. They were told that for a specific variety of apples, there were two options, namely, local apples costing 10

\begin{tabular}{|c|c|c|c|c|c|}
\hline $\begin{array}{l}\text { Importance of goal in mind } \\
\text { when making a decision }\end{array}$ & No prime & Mean score for $\mathrm{g}$ & Pictorial prime & $F$-test & \multirow[b]{2}{*}{$\begin{array}{r}\text { Table } 1 . \\
\text { Impact of priming on } \\
\text { importance ratings } \\
\text { given to goals post- } \\
\text { choice decision } \\
\text { (Study 1a) }\end{array}$} \\
\hline $\begin{array}{l}\text { Price } \\
\text { Freshness } \\
\text { Local origin } \\
\text { Health } \\
\text { Well-being of local farmers }\end{array}$ & $\begin{array}{l}3.75 \\
4.33 \\
3.04 \\
3.88 \\
2.59\end{array}$ & $\begin{array}{l}3.52 \\
4.14 \\
3.20 \\
3.96 \\
2.96\end{array}$ & $\begin{array}{l}3.15 \\
4.37 \\
3.50 \\
4.25 \\
3.21\end{array}$ & $\begin{array}{l}5.51^{* * * *} \\
1.21 \\
2.31^{*} \\
2.12 \\
3.93^{* *}\end{array}$ & \\
\hline
\end{tabular}

Local food sales

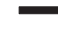


kuna (circa €1.35) per kilogram and imported apples costing 7 Kuna per kilogram (circa $€ 0.95$ ). Subjects were asked to choose between the local or imported apples or select neither. After making a choice, respondents completed a five-item scale of personal norms (Hosta and Zabkar, 2020), adapted to local foods $(\alpha=0.893)$. In addition, to further enhance understanding of choices, respondents completed the five-item scale of Lichtenstein et al. (1993) to capture price consciousness $(\alpha=0.902)$. Both scales were measured on seven-point Likert scales. The mean score on the personal norms scale in relation to local foods was 4.57, indicating that they are positively valenced. For instance, only $22.9 \%$ disagreed or strongly disagreed with the statement "I feel I have an ethical obligation to buy local products."

\section{Results and discussion}

In contrast to Study 1a and $H 1$, there was no significant difference between the three conditions regarding the likelihood of selecting the local option $\left(X^{2}=4.026, p=0.134\right)$. What is most striking about the pattern of choices is the difference in the no prime control group. In Study 1a, only $51 \%$ of the control group selected the local food option but this increased to $68 \%$ in Study 1b. Several reasons could explain this discrepancy. It could be that "imported" provides less certainty than Poland. For instance, "imported" could include countries with perceived poor food safety and also goods from Serbia for which some Croatians feel animosity (Brečić et al., 2013). These motives for import avoidance are not primed in the PoS materials developed. Second, Study 1b occurred during March/April 2020, when there was considerable disruption to food shopping behavior because of the Coronavirus crisis, with residents subject to lockdown restrictions. During this period the sentiment to help fellow Croatians in a time of crisis was widespread, with retailers running campaigns to support local producers and achieve self-sufficiency (Wynne-Jones, 2020). If buying local concerns are paramount in consumers' minds, then aide-mémoire priming becomes superfluous.

To understand choices further, we ran a logistic regression model with choice as the dependent variable $(1=$ chose local; $0=$ chose imported), and price consciousness and personal norms relating to local foods as independent variables, along with dummies for being exposed to the pictorial and textual primes (Table 2).

Table 2 indicates that price consciousness, as may be expected, decreases the likelihood of selecting the more expensive, local option. In contrast, personal norms related to local food strengthen the likelihood of selecting the local option, indicating that personal values affect the demand for local food. The textual primes, however, in Study $1 \mathrm{~b}$ do not have a significant effect on consumer choice, while the pictorial one has a positive effect at the $10 \%$ level of significance only.

Table 2.

Logistic regression model for choice of local option (Study 1b)

\begin{tabular}{lrrrrr}
\hline Variable & B & SE & Wald & Exp (b) & Sig. \\
\hline Intercept & -0.255 & 0.736 & 0.120 & 0.775 & 0.729 \\
Personal norms toward local food & 0.431 & 0.128 & 11.412 & 1.538 & 0.001 \\
Price consciousness & -0.225 & 0.113 & 3.945 & 0.799 & 0.047 \\
Picture prime & 0.618 & 0.356 & 3.009 & 0.539 & 0.083 \\
Textual prime & 0.242 & 0.385 & 0.397 & 1.274 & 0.529 \\
Note: Dependent variable = chose local apples option & & & & \\
\end{tabular}


In summary, Study $1 \mathrm{~b}$ advances understanding regarding the role of price consciousness and personal norms. However, we are unable to rule out the confound between a specific $\mathrm{COO}$ and local versus imported products generally. Differences in the control group's choices between Studies1a and $1 \mathrm{~b}$ lead to inconsistent results relating to $H 1$ across the two studies. Recognizing the limitations of a computer lab-based setting, we now turn attention to the field experiment.

\section{Study 2}

Study 2 tests the effectiveness of PoS priming for local foods in a supermarket setting, using loyalty card data to consider differences across consumer segments.

\section{Design and procedure}

The field experiment occurred in three countries (Croatia, Slovenia and Serbia). We adapted PoS materials to the specific country with textual messages translated and back translated by bilingual speakers to ensure consistency. The experiment occurred in the stores of one of the largest grocery retail chains in South-eastern Europe. It sells significant quantities of both local and imported fruits, and the company estimates that it purchases more than 190,000 tons of fruits and vegetables per annum.

The experiment involved apples as a product category in all countries. In total, 18 stores were included in the field experiment for apples ( 6 per country comprising 2 Pictorial PoS, 2 Textual PoS and 2 control stores). The retailer recommended stores with similar sales and customer profiles for inclusion and the selected stores had the same format and size (supermarkets) within a country. To test that the results were not unique to this specific product, we also undertook the experiment with cherries in a further six stores in Croatia. In each store, local apples/cherries were sold physically juxtaposed to the imported ones, to ensure equal choice for consumers. The retail space devoted to local and imported apples/ cherries was equal and uniform across all stores. The experiment ran for two weeks in all stores. Across all stores, the price of the imported apples was 9 Kuna $(€ 1.21)$ per kilogram and for local apples 10 Kuna (€1.35) per kilogram, with prices set by the retailer. These are typical retail prices for such products. Imported apples came from Poland, which is the largest apple producer in Central and Eastern Europe. Poland is not subject to any widespread animosity in the three countries studied. Similar arrangements (e.g. price differential and import source) occurred for cherries in Croatia.

Care was taken to select retail stores of a similar size and location characteristics for inclusion in the experiment. For Croatia, where loyalty card data were available, we checked the profile characteristics of shoppers who frequented control and treatment stores (Table 3).

Table 3 reveals all the profile characteristics (fruit and vegetable expenditure patterns, age, gender, market segment weighting) were statistically indistinguishable between the control and treatment samples.

\section{Results}

Sales data. Table 4 summarizes unit sales data for apples and cherries, respectively, across the three store groups (no treatment, textual PoS and pictorial PoS). In all cases, the share of sales accounted for by the local version is higher where either the textual or pictorial-based PoS materials are present compared with the control group where the same products and prices were in store but without any PoS material. In the control group stores, imports account for approximately two-thirds of sales, although this varies across countries and is also higher for cherries compared to apples. The percentage share of sales accounted for by the local version is highest in the case of the pictorial-based PoS material. Noticeably, the 
market share of the local food option is lower in the field experiment compared against the hypothetical purchase scenarios in Studies $1 \mathrm{a}$ and $1 \mathrm{~b}$.

Loyalty card data. We followed the approach of Gertler (2004) to evaluate the intervention, considering the effect of exposure to the textual and pictorial primes on the likelihood of purchasing the local food option. We estimated a logistic regression of the probability of purchasing the local food version, where purchasing the local version was coded $=1$ and imported equivalent coded 0 . The key independent variables were dummies indicating whether the individual was exposed to textual PoS or pictorial PoS materials. The lack of self-selection issues and the fact that the control and treatment samples are well-balanced in the observed characteristics imply that a simple comparison of mean outcomes will likely provide an unbiased estimate of priming impacts. However, the analysis also controlled for profile characteristics to reduce idiosyncratic variation and to improve the power of the estimates (Gertler, 2004). The specific variables included in the model were: average value of purchase of fresh fruit and vegetables in the previous year, age and gender of the loyalty card owner. The analysis draws on data for 6,051 loyalty card users.

We estimated the model for the full sample and for specific market segments. This reflects that the effect of priming may vary across consumer groups. Based on data mining,

\section{Table 3.}

Descriptive statistics for treatment and control groups based on loyalty card data, available for Croatia only (Study 2)

\begin{tabular}{lccc}
\hline Variable & Treatment & Control & $\begin{array}{c}p \text {-value for } \\
\text { difference }\end{array}$ \\
\hline $\begin{array}{l}\text { Average weekly expenditure on fruit and vegetables per in } \\
\text { previous year (Kuna) }\end{array}$ & 21.71 & 21.69 & 0.989 \\
Average quantity (kg) of fruit and vegetables bought in & & & \\
previous year (Kg) & 2.838 & 2.753 & 0.700 \\
Number of household members & 1.981 & 1.882 & 0.981 \\
Age (years) & 56.10 & 57.07 & 0.980 \\
Women (\% of shoppers) & 67.93 & 68.93 & 0.543 \\
Just affordable segment \% of total shoppers) & 16.64 & 17.89 & 0.699 \\
Healthy segment (\% of total shoppers) & 4.18 & 4.27 & 0.928 \\
Traditional segment (\% of total shoppers) & 16.43 & 14.89 & 0.136 \\
Tasty and high quality segment (\% of total shoppers) & 18.86 & 18.04 & 0.451
\end{tabular}

Notes: The $p$ values in the third column are for the test of the hypothesis that the means of continuous variables in the treatment and control groups are the same and relate to $X^{2}$ tests in the case of categorical variables

Average weekly expenditure on fruit and vegetables per in

Average quantity $(\mathrm{kg})$ of fruit and vegetables bought in

previous year $(\mathrm{Kg})$

Age (years)

Women ( $\%$ of shoppers)

Just affordable segment $\%$ of total shoppers)

variables 
the retailer segments their loyalty card holders into six types, namely, just affordable (price the most important factor, a high share of discounted products), tasty and high quality (buy more expensive brands, a higher share of delicatessen goods and wines), moderate (mediumpriced brands), fast and practical (high share of ready to eat products and quick preparation foods), traditional (high relative share of fresh meat and vegetables, above-average share of discounted products) and healthy (high share of fruit, vegetables and fish, Mediterranean cuisine). The retailer's typology, thus derives from actual spending patterns, rather than stated preferences or an academic framework. Some cardholders because they are infrequent shoppers at the retailer are not classified into any segment. The results of the logistic regressions, reported in log odds, are presented in Table 5.

The estimates suggest that for the full sample shoppers exposed to the textual PoS material were $31.9 \%$ more likely than those in the control stores to purchase the local food version. Those exposed to the pictorial PoS material were $42.5 \%$ more likely than shoppers in the control stores to purchase the local food version. In both cases, the differences are statistically significant at the $5 \%$ significance level. The results thus, support $H 1$ regarding the effect of PoS materials and $H 3$ regarding the relative effectiveness of pictorial versus textual-based PoS materials.

The analysis was repeated for specific consumer segments. It is important to note that compared with the full sample analysis, statistical power declines due to fewer observations and the odds ratios cannot be directly compared across the models. In all cases, the odds estimates are above 1, indicating that exposure to textual and pictorial primes positively affects the likelihood of purchasing the local food version, however differences are not always statistically significant. Noticeably, in the just affordable segment, with a shopper profile consistent with low incomes, exposure to the textual PoS increases the likelihood of purchasing the local food option by $77.4 \%$ and when exposed to the pictorial PoS this group is over twice as likely to purchase the local food version than in the control stores without the PoS.

Two groups where priming appears less effective are the tasty and quality and fast and practical segments. The tasty and quality group has the highest propensity to purchase the local food option in the control scores compared against the rest of the sample (Table 6), so in this case, the benefits of local foods may already be salient in shoppers' minds at the point of purchase, so the PoS materials are relatively less effective. The fast and practical segment also has a relatively high likelihood of purchasing the local version in the control stores and also purchases a higher proportion of convenience food, looking to minimize time in store. This group may be less likely to notice and process PoS materials, although we do not have

\begin{tabular}{lcc}
\hline Group & Textual PoS & Pictorial PoS \\
\hline Full sample & $1.319(0.025)$ & $1.425(0.002)$ \\
Just affordable segment only & $1.774(0.053)$ & $2.027(0.028)$ \\
Healthy segment only & $1.296(0.643)$ & $2.487(0.043)$ \\
Fast and practical only & $1.237(0.458)$ & $1.281(0.332)$ \\
Moderate segment only & $1.538(0.138)$ & $1.684(0.054)$ \\
Tasty and quality segment only & $1.309(0.320)$ & $1.152(0.563)$
\end{tabular}

Notes: The columns report the estimated $\log$ odds from the co-efficient $n$ the dummy variables relating to whether the shopper was exposed to the textual or pictorial PoS materials compared against the control of no PoS. The $p$ value for the hypothesis test that the estimated log odds is equal to 1 is reported in parentheses

Local food sales

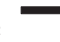


observational data to evaluate this. The healthy segment is small, and, in this case, the pictorial PoS material is far more effective than textual PoS. For this group, the image of a healthy and strong young farmer may be particularly effective and be far more proximate than textual statements.

In summary, Study 2 provides support for $H 1$ regarding the effect of PoS materials on consumer behavior and $H 3$ regarding the relative effectiveness of pictorial versus textualbased PoS materials.

\section{Discussion}

Ethical consumption involves:

[...] people purchasing and using products and resources according not only to the personal pleasures and values they provide but also to ideas of what is right and good, versus wrong and bad, in a moral sense (Starr, 2009, p. 916)

Local foods are a form of ethical consumption as their appeal in part rests on altruistic motivations and normative judgments regarding supporting local farmers and producers (Birch et al., 2018; Megicks et al., 2012). While interest in ethical and socially responsible products is growing (MINTEL, 2013), such goods may suffer from an intention-behavior gap in consumer behavior. As found in the differences between the percentage of shoppers selecting more expensive local apples in hypothetical lab experiments (Studies 1a and 1b) and a field experiment where consumers spend their own money (Study 2), the intentionbehavior gap can be large.

As noted by Govind et al. (2019, p. 1195), "literature has identified but not explored much" reasons for the intention-behavior gap in ethical consumption, with a need to consider strategies to reduce the discrepancy. This paper contributes by drawing on priming theory to theorize the effectiveness of aide-mémoire priming at the point of decisionmaking. This recognizes that intentions may remain unacted due to memory lapses (simply forgetting to do what was intended) and competing goals "crowding out" or overriding the achievement of others in a particular context and time period (Rogers and Milkman, 2016). The field experiment reveals that priming goals can significantly increase the likelihood of purchasing products consistent with that behavioral goal. Study la contributes by demonstrating the mechanisms underpinning the effectiveness of aide-mémoire priming, namely, increasing the salience of goal consistent mechanisms in decision-making at the expense of means to achieve non-primed goals.

CLT suggests that advertising messages are more effective when they evoke construal levels that are congruent with viewers' psychological distance (Martin et al., 2009), with pictures more persuasive for proximal consumption events, while text is preferable for distant consumption events (Choi et al., 2019; Lee et al., 2009). We advance knowledge by

Table 6.

Responsiveness to PoS materials based on consumer segment type (Study 2)

\begin{tabular}{lccc}
\hline Retailer's segment & No treatment $(\%)$ & $\begin{array}{c}\text { \% buying local version } \\
\text { Textual PoS }(\%)\end{array}$ & Pictorial PoS (\%) \\
\hline Fast and practical & 33.6 & 38.8 & 38.5 \\
Healthy & 36.8 & 44.4 & 53.5 \\
Just affordable & 19.4 & 27.7 & 31.1 \\
Moderate & 28.2 & 37.6 & 39.8 \\
Tasty and high quality & 36.7 & 43.1 & 40.0 \\
Traditional & 26.7 & 33.1 & 32.2 \\
\hline
\end{tabular}


testing CLT theory in the context of retail primes and a field experiment for the first time. While both textual and pictorial primes are effective in the field, results are consistent with CLT in that pictures have a stronger effect for the proximal consumption event (fruit purchase in store). This has implications for the design of in-store marketing communications.

Finally, the paper contributes to the burgeoning literature on local foods, which calls for research to generate "a better understanding of local food messaging" and its effectiveness (Abrams and Soukup, 2017 p. 14). The results demonstrate, for the first time in a field experiment, that exposure to marketing materials in-store significantly affects the likelihood of purchasing local foods. Study 1a indicates that marketing materials may increase the salience of local origin and the well-being of local farmers in consumer choices and suppress price considerations. This is consistent with notions that consumers of local foods are flexible consumers (McEachern et al., 2010); with a range of goals, that may conflict and not be resolved consistently. Consequently, behavior is context-dependent (Bargh, 2017; Cadario and Chandon, 2020), and thus, amenable to influence from marketing materials where they promote goals with a positive valence.

\section{Managerial implications}

The research generates actionable insights for retailers and their suppliers, as well as those who wish to promote the demand for local foods. Study 2 demonstrates that PoS primes can increase sales of more expensive local foods in a supermarket environment. Inducing shoppers to trade up to more expensive local foods, even where they are positively regarded by consumers, is a major challenge (MINTEL, 2013). PoS materials can be effective in boosting demand.

The analysis identifies that the appeal of local foods varies significantly across consumer segments, with the likelihood of purchase higher among healthy, tasty and high quality and fast and practical segments compared against the just affordable group. Among the latter, either with or without priming the likelihood of purchase is lowest. However, priming still has a significant effect on the just affordable group's likelihood of purchase. The descriptor of primes as nudges (Thaler and Sunstein, 2003), which can influence consumer behavior, but where outcomes depend on the starting position, appears particularly apt.

For retailers, PoS materials may be particularly effective primes as viewing occurs at the point at which purchases occur, reducing the chance of memory lapses and providing an almost instantaneous opportunity for individuals to makes choices consistent with an activated goal. Consequently, the possibility of goal fulfillment and the satisfaction it generates is strong and quick (Sela and Shiv, 2009). PoS materials have another advantage for retailers in that they are typically a low-cost investment, providing a means for improving demand for local food through a straightforward modification of the in-store shopping environment (Campbell and Fairhurst, 2016). While both pictorial and textualbased PoS materials are effective in-store, for proximal consumption events, such as purchasing fruit, pictures appear preferable.

The results provide insights as to when PoS materials should be deployed and will be most effective. For retailers, they will be most useful when seeking to promote a behavior, which is positively regarded by consumers, but the related behavioral goal is currently crowded out in purchase decision-making. They will be less effective where consumers already perform the desired behavior (such as with the tasty and high quality market segment) or where the desired behavioral goal is already prominent in consumer decision-making so that further PoS priming is superfluous (which may explain the results of Study $2 \mathrm{~b}$ ).

Finally, this paper focuses on local foods but the potential for PoS materials to influence other retail choices in a similar manner appears promising. In Western countries, facing a 
marked increase in obesity and other diet-related health problems, the ability to affect consumers' purchases in a grocery store, where decisions shape the food consumption of several people over multiple days, is important (Wansink, 2017). Given estimates that the costs of treating ill health caused by obesity will reach $\$ 1.2 \mathrm{tn}$ globally by the year 2025 (World Obesity Federation, 2017) and the ineffectiveness of many conventional, preventative health campaigns (Kelly and Barker, 2016), low cost textual and visual PoS materials in-store may offer substantial benefits albeit only when consumers already possess health-oriented goals.

\section{Limitations and further research}

The study benefited from working with a retailer, intervening in a real shopping environment. While this aids external validity, it also involves commercial sensitivities. The researchers could not access data on the prices paid by the retailer for imported and local versions of fruits, so cannot estimate profitability. Access to loyalty card data was limited to transactions involving the purchase of the local and imported versions of fruits studied in the control and treatment stores. At the request of the retailer, we report the percentage of sales accounted for by the local and imported versions rather than absolute sales volumes.

Study 2 looks at effects on retail sales over a two-week period; a relatively short timeframe necessitated by the fact that the study deals with perishable and seasonal goods. It was not possible to procure both local and imported versions of the same product and hold prices constant over a longer time period. This curtails assessment of before and after effects. The use of less seasonal produce (e.g. cheese and hams) would more easily allow researchers to measure the post-intervention spillover effect on sales, although farmerrelated imagery may be less successful for promoting local foods in these cases given greater intermediary processing.

While Study $1 \mathrm{~b}$ provides insight into the roles of price consciousness and personal norms in motivating the selection of local foods, we are unable to rule out the confound between a specific $\mathrm{COO}$ and local versus imported products more generally. Future laboratory and field studies incorporating multiple $\mathrm{COO}$ conditions would help isolate specific COO effects from imports generally. Study 2 finds that pictorial-based PoS materials are more effective at increasing sales than textual-based ones for a psychologically close object (apples). To assess further, the applicability of CLT, researchers could analyze the effectiveness of pictorial versus textual priming also for psychologically more distant products in "local" contexts.

Finally, the research team had access to loyalty card data for transactions involving the purchase of local and imported apples and cherries with information on fruit and vegetable category expenditure. We had no access to data on the other items bought by shoppers. Future research would benefit from analyzing shopping basket data and measuring spillover effects. Two competing theories warrant testing. On the one hand, one may expect that priming in-store a goal for, say, local products in relation to fruits to spill over to increasing the propensity to buy locally produced goods in other food categories, given the relatively short delay between priming and purchase decisions. However, lab-based research identifies the potential for goal-satiation following a goal-congruent choice (Chartrand et al., 2008). So, for example, following exposure to a health-related prime and selection of a healthy choice, consumers may feel able to reward themselves by opting for less healthy goods in subsequent choices. Paradoxically, a health-related prime at the beginning of a grocery shopping experience could, thus lead to, overall, the selection of a less healthy basket of goods. The validity of these two competing claims could be tested through retail field 
experiments, using health and local primes in treatment stores and analyzing their effect on the overall composition of shopping baskets.

\section{Conclusion}

The study uses lab and field experiments combined with an analysis of loyalty card transactions to understand the ability of PoS primes to increase sales of primed-related goods. In a real shopping environment, it finds that both pictorial and textual PoS materials can be effective in increasing sales of prime-related goods. Study 1a suggests this occurs by promoting the salience of primed-related behavioral goals in decision-making and suppressing the influence of non-primed behavioral goals. The results are encouraging regarding the utility of other in-store primes, such as relating to better diets, to achieve socially desirable outcomes without recourse to changes in economic incentives or coercion.

\section{Note}

1. We thank a referee for suggesting this.

\section{References}

Abrams, K.M. and Soukup, C. (2017), "Matching local food messages to consumer motivators: an experiment comparing the effects of differently framed messages", Journal of Applied Communications, Vol. 101 No. 4, pp. 1-19.

Andrews, M., Luo, X., Fang, Z. and Aspara, J. (2014), "Cause marketing effectiveness and the moderating role of price discounts", Journal of Marketing, Vol. 78 No. 6, pp. 120-142.

Arfini, F. (2019), "EU food quality policy: geographical indications", in Dries, L., Heijman, W., Jongeneel, R., Purnhagen, K. and Wesseler, J. (Eds), EU Bioeconomy Economics and Policies, Springer International Publishing, Cham, Vol. 2, pp. 27-46.

Austin, J., Sigurdsson, S.O. and Rubin, Y.S. (2006), "An examination of the effects of delayed versus immediate prompts on safety belt use”, Environment and Behavior, Vol. 38 No. 1, pp. 140-149.

Ballings, M., McCullough, H. and Bharadwaj, N. (2018), "Cause marketing and customer profitability”, Journal of the Academy of Marketing Science, Vol. 46 No. 2, pp. 234-251.

Bargh, J.A. (2017), Before You Know It: The Unconscious Reasons We Do What We Do, William Heinemann, London.

Barjolle, D., Gorton, M., Đorđević, J.M. and Stojanović, Ž. (2013), "Food consumer science: Theories", Methods and Application to the Western Balkans, Springer, Dordrecht.

Barlagne, C., Bazoche, P., Thomas, A., Ozier-Lafontaine, H., Causeret, F. and Blazy, J.M. (2015), "Promoting local foods in small island states: the role of information policies", Food Policy, Vol. 57, pp. 62-72.

Bingen, J., Sage, J. and Sirieix, L. (2011), “Consumer coping strategies: a study of consumers committed to eating local”, International Journal of Consumer Studies, Vol. 35 No. 4, pp. 410-419.

Birch, D., Memery, J. and De Silva Kanakaratne, M. (2018), "The mindful consumer: balancing egoistic and altruistic motivations to purchase local food", Journal of Retailing and Consumer Services, Vol. 40, pp. 221-228.

Brasel, S.A. and Gips, J. (2011), "Red bull 'gives you wings' for better or worse: a double-edged impact of brand exposure on consumer performance", Journal of Consumer Psychology, Vol. 21 No. 1, pp. 57-64.

Braun, V., Clarke, V., Hayfield, N. and Terry, G. (2019), “Thematic analysis”, in Liamputtong, P. (Ed.), Handbook of Research Methods in Health Social Sciences, Springer, Singapore, pp. 843-860. 
Brečić, R., Filipović, J., Gorton, M., Ognjanov, G., Stojanović, Ž. and White, J. (2013), “A qualitative approach to understanding brand image in an international context: insights from Croatia and Serbia”, International Marketing Review, Vol. 30 No. 4, pp. 275-296.

Brown, E., Dury, S. and Holdsworth, M. (2009), "Motivations of consumers that use local, organic fruit and vegetable box schemes in Central England and Southern France", Appetite, Vol. 53 No. 2, pp. 183-188.

Cadario, R. and Chandon, P. (2020), "Which healthy eating nudges work best? A meta-analysis of field experiments”, Marketing Science, Vol. 39 No. 3, pp. 465-486.

Campbell, J.M. and Fairhurst, A.E. (2016), "Reducing the intention-to-behaviour gap for locally produced foods purchasing: the role of store, trust, and price", International Journal of Retail and Distribution Management, Vol. 44 No. 5, pp. 508-523.

Carrington, M.J., Neville, B.A. and Whitwell, G.J. (2010), "Why ethical consumers don't walk their talk: towards a framework for understanding the gap between the ethical purchase intentions and actual buying behaviour of ethically minded consumers", Journal of Business Ethics, Vol. 97 No. 1, pp. 139-158.

Carrington, M.J., Neville, B.A. and Whitwell, G.J. (2014), "Lost in translation: exploring the ethical consumer intention-behavior gap", Journal of Business Research, Vol. 67 No. 1, pp. 2759-2767.

Chabris, C.F., Heck, P.R., Mandart, J., Benjamin, D.J. and Simons, D.J. (2019), "No evidence that experiencing physical warmth promotes interpersonal warmth", Social Psychology, Vol. 50 No. 2, pp. 127-132.

Chambers, S., Lobb, A., Butler, L., Harvey, K. and Traill, B.W. (2007), "Local, national and imported foods: a qualitative study", Appetite, Vol. 49 No. 1, pp. 208-213.

Chartrand, T.L., Huber, J., Shiv, B. and Tanner, R.J. (2008), "Nonconscious goals and consumer choice”, Journal of Consumer Research, Vol. 35 No. 2, pp. 189-201.

Choi, Y.K., Yoon, S., Kim, K. and Kim, Y. (2019), “Text versus pictures in advertising: effects of psychological distance and product type", International Journal of Advertising, Vol. 38 No. 4, pp. 528-543.

Corradi, N., Priftis, K., Jacucci, G. and Gamberini, L. (2013), “Oops, I forgot the light on! The cognitive mechanisms supporting the execution of energy saving behaviors", Journal of Economic Psychology, Vol. 34, pp. 88-96.

Custers, R. and Aarts, H. (2005), "Positive affect as implicit motivator: on the nonconscious operation of behavioral goals", Journal of Personality and Social Psychology, Vol. 89 No. 2, pp. 129-142.

Custers, R. and Aarts, H. (2010), "The unconscious will: how the pursuit of goals operates outside of conscious awareness", Science, Vol. 329 No. 5987, pp. 47-50.

Feldmann, C. and Hamm, U. (2015), “Consumers' perceptions and preferences for local food: a review”, Food Quality and Preference, Vol. 40, pp. 152-164.

Fishbein, M. and Yzer, M.C. (2003), "Using theory to design effective health behavior interventions", Communication Theory, Vol. 13 No. 2, pp. 164-183.

Fitzsimons, G.J., Fitzsimons, G.M. and Chartrand, T.L. (2008), "Automatic effects of brand exposure on motivated behavior: how apple makes you think different", Journal of Consumer Research, Vol. 35 No. 1, pp. 21-35.

Fransen, M.L., Fennis, B.M., Pruyn, A.T.H. and Das, E. (2008), "Rest in peace? Brand-induced mortality salience and consumer behavior", Journal of Business Research, Vol. 61 No. 10, pp. 1053-1061.

FUTERRA (2005), The Rules of the Game: Principles of Climate Change Communications, FUTERRA Sustainability Communications Ltd, London.

Gertler, P. (2004), "Do conditional cash transfers improve child health? Evidence from PROGRESA's control randomized experiment”, American Economic Review, Vol. 94 No. 2, pp. 336-341. 
Govind, R., Singh, J.J., Garg, N. and D'Silva, S. (2019), "Not walking the walk: how dual attitudes influence behavioral outcomes in ethical consumption”, Journal of Business Ethics, Vol. 155 No. 4, pp. 1195-1214.

Hernandez, J. M. D C., Wright, S.A. and Ferminiano Rodrigues, F. (2015), "Attributes versus benefits: the role of construal levels and appeal type on the persuasiveness of marketing messages", Journal of Advertising, Vol. 44 No. 3, pp. 243-253.

Hosta, M. and Zabkar, V. (2020), "Antecedents of environmentally and socially responsible sustainable consumer behavior", Journal of Business Ethics.

Jin, L. and He, Y. (2013), "Designing service guarantees with construal fit: effects of temporal distance on consumer responses to service guarantees”, Journal of Service Research, Vol. 16 No. 2, pp. 202-215.

Karremans, J.C., Stroebe, W. and Claus, J. (2006), "Beyond Vicary's fantasies: the impact of subliminal priming and brand choice", Journal of Experimental Social Psychology, Vol. 42 No. 6, pp. 792-798.

Kelly, M.P. and Barker, M. (2016), "Why is changing health-related behaviour so difficult?", Public Health, Vol. 136, pp. 109-116.

Kneafsey, M. (2012), "Local foods and short supply chains: consumer and producer perspectives", Local Agriculture and Short Food Supply Chains, European Commission, Brussels.

Kopetz, C.E., Kruglanski, A.W., Arens, Z.G., Etkin, J. and Johnson, H.M. (2012), “The dynamics of consumer behavior: a goal systemic perspective", Journal of Consumer Psychology, Vol. 22 No. 2, pp. 208-223.

Köpetz, C., Faber, T., Fishbach, A. and Kruglanski, A.W. (2011), "The multifinality constraints effect: how goal multiplicity narrows the means set to a focal end", Journal of Personality and Social Psychology, Vol. 100 No. 5, pp. 810-826.

Lagerkvist, C.J. and Okello, J. (2016), "Using the integrative model of behavioral prediction and censored quantile regression to explain consumers' revealed preferences for food safety: Evidence from a field experiment in Kenya”, Food Quality and Preference, Vol. 49, pp. 75-86.

Laran, J., Dalton, A.N. and Andrade, E.B. (2011), "The curious case of behavioral backlash: Why brands produce priming effects and slogans produce reverse priming effects", Journal of Consumer Research, Vol. 37 No. 6, pp. 999-1014.

Lee, A.Y., Keller, P.A. and Sternthal, B. (2009), "Value from regulatory construal fit: the persuasive impact of fit between consumer goals and message concreteness", Journal of Consumer Research, Vol. 36 No. 5, pp. 735-747.

Leonidou, C.N. and Leonidou, L.C. (2011), "Research into environmental marketing/ management: a bibliographic analysis", European Journal of Marketing, Vol. 45 Nos 1/2, pp. 68-103.

Lichtenstein, D.R., Ridgway, N.M. and Netemeyer, R.G. (1993), "Price perceptions and consumer shopping behavior: a field study”, Journal of Marketing Research, Vol. 30 No. 2, pp. 234-245.

Mandel, N. and Johnson, E.J. (2002), "When web pages influence choice: effects of visual primes on experts and novices”, Journal of Consumer Research, Vol. 29 No. 2, pp. 235-245.

Martin, B.A.S., Gnoth, J. and Strong, C. (2009), "Temporal construal in advertising", Journal of Advertising, Vol. 38 No. 3, pp. 5-20.

Martinez, S., Da Pra, M., Pollack, S., Ralston, K. and Smith, T. (2010), Local Food Systems: Concepts, Impacts, and Issues, USDA, Washington, DC.

McEachern, M.G., Warnaby, G., Carrigan, M. and Szmigin, I. (2010), "Thinking locally, acting locally? Conscious consumers and farmers' markets", Journal of Marketing Management, Vol. 26 Nos 5/6, pp. 395-412. 
Megicks, P., Memery, J. and Angell, R.J. (2012), "Understanding local food shopping: unpacking the ethical dimension", Journal of Marketing Management, Vol. 28 Nos 3/4, pp. 264-289.

MINTEL (2013), Provenance in Food and Drink - UK, Mintel Group Ltd, London.

Onozaka, Y. and McFadden, D.T. (2011), "Does local labeling complement or compete with other sustainable labels? A conjoint analysis of direct and joint values for fresh produce claim", American Journal of Agricultural Economics, Vol. 93 No. 3, pp. 689-702.

Orbell, S., Hodgkins, S. and Sheeran, P. (1997), "Implementation intentions and the theory of planned behavior", Personality and Social Psychology Bulletin, Vol. 23 No. 9, pp. 945-954.

Racine, E.F., Mumford, E.A., Laditka, S.B. and Lowe, A.E. (2013), "Understanding characteristics of families who buy local produce", Journal of Nutrition Education and Behavior, Vol. 45 No. 1, pp. 30-38.

Reczek, R.W. and Irwin, J.R. (2015), "Ethical consumption", in Norton, M.I., Rucker, D.D. and Lamberton, C. (Eds), The Cambridge Handbook of Consumer Psychology, Cambridge University Press, Cambridge, pp. 507-529.

Rogers, T. and Milkman, K.L. (2016), "Reminders through association”, Psychological Science, Vol. 27 No. 7, pp. 973-986.

Sela, A. and Shiv, B. (2009), "Unraveling priming: when does the same prime activate a goal versus a trait?", Journal of Consumer Research, Vol. 36 No. 3, pp. 418-433.

Shah, J.Y. and Kruglanski, A.W. (2003), "When opportunity knocks: bottom-up priming of goals by means and its effects on self-regulation", Journal of Personality and Social Psychology, Vol. 84 No. 6, pp. 1109-1122.

Shah, J.Y., Friedman, R. and Kruglanski, A.W. (2002), "Forgetting all else: on the antecedents and consequences of goal shielding", Journal of Personality and Social Psychology, Vol. 83 No. 6, pp. 1261-1280.

Starr, M.A. (2009), "The social economics of ethical consumption: theoretical considerations and empirical evidence", The Journal of Socio-Economics, Vol. 38 No. 6, pp. 916-925.

Thaler, R.H. and Sunstein, C.R. (2003), "Libertarian paternalism”, American Economic Review, Vol. 93 No. 2, pp. 175-179.

Toler, S., Briggeman, B.C., Lusk, J.L. and Adams, D.C. (2009), "Fairness, farmers markets, and local production", American Journal of Agricultural Economics, Vol. 91 No. 5, pp. 1272-1278.

Tregear, A. and Ness, M. (2005), "Discriminant analysis of consumer interest in buying locally produced foods", Journal of Marketing Management, Vol. 21 Nos 1/2, pp. 19-35.

Trope, Y., Liberman, N. and Wakslak, C. (2007), "Construal levels and psychological distance: effects on representation, prediction, evaluation, and behavior", Journal of Consumer Psychology, Vol. 17 No. 2, pp. 83-95.

Van Doorn, J. and Verhoef, P.C. (2015), "Drivers of and barriers to organic purchase behavior", Journal of Retailing, Vol. 91 No. 3, pp. 436-450.

Van Loo, E.J., Caputo, V., Nayga, R.M. and Verbeke, W. (2014), “Consumers' valuation of sustainability labels on meat", Food Policy, Vol. 49, pp. 137-150.

Veltkamp, M., Custers, R. and Aarts, H. (2011), "Motivating consumer behavior by subliminal conditioning in the absence of basic needs: striking even while the iron is cold", Journal of Consumer Psychology, Vol. 21 No. 1, pp. 49-56.

Verplanken, B. and Holland, R.W. (2002), "Motivated decision making: effects of activation and self-centrality of values on choices and behavior", Journal of Personality and Social Psychology, Vol. 82 No. 3, pp. 434-447.

Wansink, B. (2017), "Healthy profits: an interdisciplinary retail framework that increases the sales of healthy foods", Journal of Retailing, Vol. 93 No. 1, pp. 65-78. 
Weatherell, C., Tregear, A. and Allinson, J. (2003), "In search of the concerned consumer: UK public perceptions of food, farming and buying local”, Journal of Rural Studies, Vol. 19 No. 2, pp. 233-244.

Local food sales

Weingarten, E., Chen, Q., McAdams, M., Yi, J., Hepler, J. and Albarracín, D. (2016), "From primed concepts to action: a meta-analysis of the behavioral effects of incidentally presented words", Psychological Bulletin, Vol. 142 No. 5, pp. 472-497.

World Obesity Federation (2017), Treat Obesity Now to Avoid the Consequences, World Obesity Federation, London.

Wynne-Jones, S. (2020), “Croatia's Konzum to increase sales of local fresh produce”, European Supermarket Magazine.

Yang, Y., Hobbs, J.E. and Natcher, D.C. (2020), “Assessing consumer willingness to pay for arctic food products", Food Policy, Vol. 92, p. 101846.

Zapata, L.B., Pazol, K., Rollison, J.M. and Loyola Briceno, A.C. (2018), "Family planning reminder systems: an updated systematic review", American Journal of Preventive Medicine, Vol. 55 No. 5 , pp. 716-724. 
EJM

Figure A1.

Images of point of sale materials

Appendix. Point of sale materials

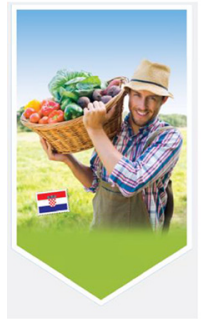

(a)

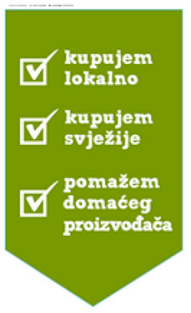

(b)

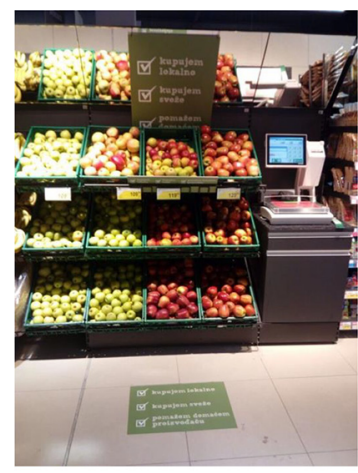

(c)

Notes: (a) Pictorial PoS image; (b) textual PoS material; (c) example of PoS materials In Store

Corresponding author

Ružica Brečić can be contacted at: rbrecic@efzg.hr

For instructions on how to order reprints of this article, please visit our website: www.emeraldgrouppublishing.com/licensing/reprints.htm

Or contact us for further details: permissions@emeraldinsight.com 